\title{
Estrategias de tres especies arbustivas del Monte frente al estrés hídrico y su relevancia para la restauración
}

\author{
MARÍA E. FernÁNDEZ ${ }^{\bowtie}$ \\ Instituto Argentino de Investigaciones de las Zonas Áridas (IADIZA), Centro Científico Tecnológico Mendoza - CONICET.
}

\begin{abstract}
RESUMEN. Conocer las diferentes estrategias de las especies arbustivas de zonas áridas permite seleccionarlas para restaurar un sitio determinado. De acuerdo con el esquema de estrategias de Grime, las plantas de zonas áridas divergen principalmente en dos tipos: por un lado, estrés-tolerantes; por el otro, ruderales. Los objetivos fueron evaluar el efecto de tres niveles de estrés hídrico sobre el crecimiento y sobre algunos caracteres ecofisiológicos de Atriplex lampa, Larrea cuneifolia y Senecio subulatus, y determinar las estrategias de estas especies frente al estrés hídrico para poder seleccionarlas luego en programas de restauración. Para ello se aplicaron tres niveles de estrés hídrico (se regó cuando el contenido hídrico del suelo disminuyó hasta 50, 70 y 85\%, control, estrés hídrico moderado y severo, respectivamente) a 60 plantines por especie en invernáculo, se construyeron curvas presión-volumen y se determinó el peso seco, parámetros hídricos, índices ecofisiológicos asociados a la tolerancia a la sequía, y se obtuvieron las estrategias según Grime mediante la herramienta StrateFy. En condiciones de estrés hídrico severo, las tres especies acumularon menos materia seca y disminuyeron su área foliar, y el crecimiento de $S$. subulatus fue el que más se vio afectado. Atriplex lampa y L. cuneifolia mostraron un bajo contenido de materia seca foliar, y A. lampa presentó menor área foliar específica. A través de estos caracteres foliares se clasificaron las tres especies como estrés-tolerantes según Grime. También, se observó que A. lampa y L. cuneifolia realizan ajuste osmótico en condiciones de estrés hídrico, mientras que S. subulatus mantiene potenciales hídricos altos y no modifica sus parámetros hídricos. Ante lo expuesto, S. subulatus presenta pocos mecanismos para enfrentar el estrés hídrico y podría utilizarse para restaurar micrositios donde se acumule agua, mientras que por sus características estrés-tolerantes, A. lampa y L. cuneifolia se recomiendan para usarlas ampliamente en la restauración de áreas degradadas del Monte.
\end{abstract}

[Palabras clave: estrés-tolerante, ruderal, triángulo de Grime, curvas presión-volumen, Atriplex lampa, Larrea cuneifolia, Senecio subulatus]

\begin{abstract}
Water stress coping strategies for three shrub species of the Monte desert and their relevance for restoration. Knowing the different strategies of shrub species in arid zones allows selecting them to restore a specific site. According to Grime's strategy scheme, plants of arid zones diverge into two main types: stresstolerant, on the one hand, and ruderal, on the other. The objective of this study was to evaluate the adaptations to water stress of three shrub species (Atriplex lampa, Larrea cuneifolia and Senecio subulatus) widely distributed along the Monte region, as to be able to select them properly in future restoration projects. Three levels of water stress (watered when soil water content decreased by 50,70 and $85 \%$, control, moderate and severe water stress, respectively) were applied to 60 seedlings per species in a glasshouse study; pressure-volume curves were obtained and then, dry weight, tissue water relations parameters and ecophysiological indices associated with drought tolerance were measured. The strategies according to Grime were obtained using the StrateFy tool. Under severe water stress, the three species accumulated less dry matter and decreased their leaf area, and the growth of S. subulatus was the most affected. A. lampa and L. cuneifolia showed low leaf dry matter content, and A. lampa had the lowest specific leaf area. Through these foliar characters, the three species were classified as stress-tolerant according to Grime. Besides, A. lampa and L. cuneifolia perform osmotic adjustment under water stress conditions, while $S$. subulatus maintains high water potentials and does not modify its hydric parameters under these conditions. Therefore, $S$. subulatus has few mechanisms to cope with water stress and could be used to restore microsites where water accumulates, while A. lampa and L. cuneifolia, due to their stress-tolerant characteristics, are recommended for wide use to restore degraded areas of the Monte region.
\end{abstract}

[Keywords: stress-tolerator, ruderal, Grime's triangle, pression-volume curves, Atriplex lampa, Larrea cuneifolia, Senecio subulatus]

Editor asociado: Alejandro Bisigato 两 mefernandez@conicet-mendoza.gob.ar
Recibido: 10 de Diciembre de 2019

Aceptado: 17 de Febrero de 2020 


\section{INTRODUCCIÓN}

La restauración ecológica en zonas áridas se enfrenta a múltiples desafíos, de los cuales uno de los más importantes es la escasez de agua, que generan gran preocupación. Si a su vez se tiene en cuenta las predicciones del cambio climático, resulta difícil proponer estrategias que no impliquen invertir grandes cantidades de recursos en suministrar agua al ecosistema degradado. Por ello, uno de los pasos clave para mejorar el éxito de la restauración sin aumentar los costos es seleccionar correctamente las especies adaptadas y capaces de sobrevivir a una escasez extrema de agua (Padilla and Pugnaire 2004; Padilla et al. 2009; Adhikari and White 2014; Pérez et al. 2019a). En muchas ocasiones, la selección de especies en programas de restauración se realiza en base a la disponibilidad de semillas o al conocimiento previo sobre su cultivo, lo que luego origina altas mortandades a campo. Para poder seleccionar las especies de manera correcta es necesario conocer las estrategias adaptativas al estado de juvenil, ya que las plantas trasplantadas a campo son muy sensibles hasta que su sistema radical se establece bien en el suelo (Oliet et al. 2002; Bateman et al. 2018).

De forma análoga, el establecimiento natural de plantas en zonas áridas está limitado por el agua (Fisher et al. 1988; de Villalobos and Peláez 2001), principal factor que controla los procesos biológicos en zonas áridas (Noy-Meir 1973). La presencia de adaptaciones a la sequía en el estado de plántula puede determinar el establecimiento de las especies en estas áreas (Villagra and Cavagnaro 2006; Bosco et al. 2018). Conocer las diferentes estrategias que presentan las especies de zonas áridas permite evaluar si son adecuadas para ser utilizadas en la restauración de un determinado sitio en función de su capacidad para adquirir recursos, tolerar la sequía, aclimatarse al sitio, y la posible respuesta a las variaciones asociadas al cambio global entre otras (Valladares et al. 2004; Vallejo et al. 2012; Bochet and GarcíaFayos 2015; Pérez et al. 2019a).

De acuerdo con el esquema de estrategias de Grime (1977, 2006), que clasifica las especies en competidoras (C), estrés-tolerantes (S) y ruderales (R), Pierce et al. (2017) desarrollaron una herramienta calibrada a nivel global para determinar el tipo de estrategia de las plantas basándose en tres caracteres a nivel foliar (área foliar, área foliar específica y contenido de materia seca foliar). Con una base de datos global, la aplicación de esta herramienta mostró que las plantas de zonas áridas divergen principalmente en dos tipos de estrategias: estrés-tolerantes, por un lado, y ruderales, por el otro. Las especies estrés tolerantes protegen el funcionamiento metabólico en estos ambientes variables y con pocos recursos invirtiendo sobre todo en retener recursos y reparar componentes celulares en tejidos densos y persistentes. Las especies ruderales invierten una gran proporción de recursos en propágulos a partir de los cuales la población puede regenerarse frente a repetidas destrucciones de biomasa o frente a disturbios (Grime 1977, 2006; Pierce et al. 2017).

Por otro lado, la gran heterogeneidad ambiental de los desiertos determinó que las especies posean diversas adaptaciones morfológicas y fisiológicas que les permiten crecer y desarrollarse en estos ambientes extremos. Algunas especies pueden acumular compuestos osmóticamente activos y así disminuir su potencial osmótico. Esto les permite mantener la turgencia en hojas con un bajo potencial agua y mantener la absorción hídrica desde el suelo (Lambers et al. 2008; Delatorre-Herrera et al. 2010; Passera et al. 2010). A su vez, las variaciones en la elasticidad de las paredes celulares permiten mantener la turgencia (Martínez et al. 2007; Lambers et al. 2008). En estos ambientes también existen especies con tipos fotosintéticos C3, C4 y CAM, con distintas eficiencias en el uso del agua y tolerancia a la temperatura (Passera et al. 2010; Villagra et al. 2011). Caracteres morfológicos como área foliar pequeña, cutículas gruesas, baja relación vástago/raíz, alta densidad estomática y pubescencia foliar densa son otras adaptaciones que les permiten disminuir la pérdida de agua, bajar la temperatura de la hoja o aumentar la eficiencia en el uso del agua a estas especies de zonas desérticas (Sandquist and Ehleringer 1998; Galmés et al. 2011).

Las zonas áridas de la Argentina muestran un nivel de degradación moderado a severo, y se sugirió que las actividades humanas serían las causas principales de estos procesos (Roig et al. 1991; Abraham 2002). La región biogeográfica del Monte se localiza en la parte oeste de la Argentina, donde cubre 460000 $\mathrm{km}^{2}$ (Rundel et al. 2007). Posee déficit hídrico durante la mayor parte del año y tiene una precipitación media anual entre 30 y $350 \mathrm{~mm}$, con una temperatura media entre 13 y $18^{\circ} \mathrm{C}$ (Labraga and Villalba 2009). Es fundamental usar especies nativas en los programas 
de restauración del Monte, ya que están adaptadas a las condiciones ambientales del sitio y tienen más posibilidades de sobrevivir y establecerse (Nunes et al. 2016; Pérez et al. 2019a). Sin embargo, su uso intensivo resulta limitado por la disponibilidad de semillas y de conocimientos básicos sobre su autoecología (Vallejo et al. 2012; Rovere 2015).

En particular, las especies arbustivas del Monte son clave para ser utilizadas en programas de restauración, ya que son la forma de vida dominante de la región y presentan diversas adaptaciones al estrés hídrico que les permitieron sobrevivir en esos ambientes (Villagra et al. 2011; Fernández et al. 2016). A su vez, muchas actúan como "plantas nodrizas" al mejorar las condiciones microclimáticas, aumentar la disponibilidad de agua y nutrientes y ofrecer protección contra la herbivoría (Soriano et al. 1994; Bisigato and Bertiller 1999; Rossi and Villagra 2003). Estas condiciones pueden beneficiar la supervivencia y el crecimiento de otras especies bajo sus copas (Padilla and Pugnaire 2006; Dalmasso 2010; Bonvissuto and Busso 2013), lo cual ayuda a la revegetación natural de estos sitios.

Las estrategias de las especies arbustivas del Monte frente a la escasez de agua han sido poco estudiadas, y esto se refleja en la necesidad de generar conocimientos básicos sobre estas especies a fin de llevar a cabo eficientemente programas de restauración (Rovere 2015). Por lo tanto, este estudio pretende evaluar las adaptaciones a condiciones de estrés hídrico que presentan tres especies arbustivas distribuidas a lo largo del Monte. Para ello, los objetivos fueron: 1) evaluar el efecto de tres niveles de estrés hídrico sobre el crecimiento y algunos caracteres eco-fisiológicos (potencial osmótico, módulo de elasticidad y área foliar específica, entre otros) de Atriplex lampa (Moq.) D. Dietr., de Larrea cuneifolia Cav. y de Senecio subulatus D. Don ex Hook. and Arn. var. Subulatus, y 2) determinar las estrategias de las tres especies frente al estrés hídrico para seleccionarlas en programas de restauración. Para ello se llevó a cabo un experimento de invernáculo en el que se aplicaron tratamientos de estrés hídrico a plantines de los tres arbustos, se construyeron curvas presión-volumen, se determinaron algunas medidas de crecimiento y parámetros hídricos, y se calcularon índices ecofisiológicos asociados a la tolerancia a la sequía y las estrategias ecológicas según Grime.

\section{Materiales y Métodos}

\author{
Especies estudiadas
}

Para el presente estudio se seleccionaron tres especies arbustivas de amplia distribución a lo largo del Monte, y que fueron incluidas en diversos programas de restauración: $A$. lampa, L. cuneifolia y S. subulatus (Dalmasso 2010; Becker et al. 2013; Dalmasso and Martínez Carretero 2013; Pérez et al. 2019a) (se incluyen imágenes de las tres especies como material suplementario). A. lampa (Moq.) D. Dietr. (Amaranthaceae) es un arbusto C4, de 0.5 a $2.5 \mathrm{~m}$ de alto, que presenta altas tasas de crecimiento y tolera suelos con altas concentraciones salinas y de escasa fertilidad (Passera and Borsetto 1989; Trione and Passera 1993; Caraciolo et al. 2002; Passera et al. 2010). L. cuneifolia Cav. (Zygophyllaceae) es un arbusto C3, de hojas pequeñas, estomas con una alta resistencia y cierre estomático, y sobrevive frente a condiciones de alto estrés hídrico (Barbour et al. 1974; Fernández et al. 2016). Senecio subulatus D. Don ex Hook. and Arn. var. subulatus (Asteraceae) es una especie C3 sub-arbustiva, de hábito ruderal, con hojas carnosas, (Ruiz Leal 1972; Martínez Carretero 1993; Méndez et al. 1993; Castro et al. 2013), que presenta potenciales hídricos y conductancias estomáticas elevadas en condiciones de estrés hídrico (Fernández et al. 2015).

\section{Producción de plantas}

Las plantas de las tres especies se obtuvieron a partir de semillas recolectadas en la localidad de Agrelo, al SO de Mendoza, Argentina

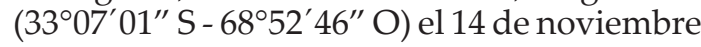
de 2013 (A. lampa y S. subulatus), y el 16 de enero de 2014 (L. cuneifolia). Las semillas fueron almacenadas en bolsas de papel a temperatura ambiente hasta el inicio de los ensayos. Para obtener las semillas de A. lampa y L. cuneifolia se frotaron los frutos entre dos planchas de goma corrugada y sólo se usaron las semillas bien conformadas. Las de $L$. cuneifolia se lavaron con agua corriente durante $48 \mathrm{~h}$ para romper su dormición química (Fernández et al. 2019). Las semillas de $A$. lampa y $S$. subulatus no requieren de ningún tratamiento pre-germinativo (Passera 1990; Masini et al. 2016). Antes de la siembra, las semillas fueron desinfectadas con una solución comercial de hipoclorito de sodio $(60 \mathrm{~g} \mathrm{Cl} / \mathrm{L})$ diluida al $15 \%$, por 7 minutos, y luego fueron lavadas repetidas veces con agua estéril. Las plántulas procedentes de la siembra en 
almácigo se trasplantaron a macetas plásticas de $10 \mathrm{~cm}$ de diámetro y $2 \mathrm{~L}$ de capacidad (con orificios de drenaje), rellenas con $4.1 \mathrm{~kg}$ de suelo franco-arenoso seco al aire y tamizado (obtenido de una cantera ubicada dentro de la región del Monte, en Las Compuertas, Luján de Cuyo, Mendoza). La capacidad de campo del suelo fue de $18.8 \%$. Las plantas se mantuvieron en invernáculo de vidrio y fueron regadas, cuando fue necesario, hasta el comienzo del ensayo. En el invernáculo, la transmisión promedio de PAR medida con radiómetro al mediodía fue de $1100 \mu \mathrm{mol}_{\mathrm{m}} \mathrm{m}^{-}{ }^{2} . \mathrm{s}^{-}$ ${ }^{1}$ y la temperatura y la humedad relativa diaria promedio de los meses que duró el ensayo se presentan en la Tabla 1 (datos obtenidos a través de un datalogger Hobo U12-011).

\section{Diseño del ensayo}

Las plantas se produjeron en el invernáculo del IADIZA (Instituto Argentino de Investigaciones de las Zonas Áridas, 32 ${ }^{\circ} 3^{\prime}$ S - 68 57' O), Mendoza, Argentina, durante marzo de 2015. Las plantas de 9 meses de edad fueron sometidas a los tratamientos de estrés hídrico en diciembre de 2015 hasta principios de mayo de 2016. El diámetro del tallo y la altura del vástago promedio de los plantines al iniciar el ensayo fueron respectivamente de $2.6 \mathrm{~mm}$ y $56 \mathrm{~cm}$ para A. lampa, $1.9 \mathrm{~mm}$ y 13 $\mathrm{cm}$ para L. cuneifolia y $2.1 \mathrm{~mm}$ y $42 \mathrm{~cm}$ para S. subulatus. Los tratamientos se aplicaron en base a la disponibilidad hídrica del suelo. En el T1 (control), las plantas se regaron hasta alcanzar capacidad de campo cuando el suelo perdía el 50\% de su contenido hídrico (riegos cada 4-7 días). En el T2 (estrés hídrico moderado), se regaron cuando perdía el 70\% (riegos cada 9-15 días). En el T3 (estrés hídrico severo), se regó cuando perdía el 85\% (riegos cada 20-35 días). Los cálculos de reposición de agua se establecieron en base a diferencias

Tabla 1. Temperatura (T) y humedad relativa (HR) máxima y mínima diaria dentro del invernáculo durante los meses en los que se llevó a cabo el ensayo.

Table 1. Daily maximum and minimum temperature $\left(\mathrm{T}^{\circ}\right)$ and relative humidity (HR) inside the glasshouse during the months the experiment was carried out.

\begin{tabular}{lcccc}
\hline \multicolumn{1}{c}{ Mes } & $\begin{array}{c}\mathrm{T} \\
\text { Mínima } \\
\left({ }^{\circ} \mathrm{C}\right)\end{array}$ & $\begin{array}{c}\mathrm{T} \\
\text { Máxima } \\
\left({ }^{\circ} \mathrm{C}\right)\end{array}$ & $\begin{array}{c}\mathrm{HR} \\
\text { Mínima } \\
(\%)\end{array}$ & $\begin{array}{c}\mathrm{HR} \\
\text { Máxima } \\
(\%)\end{array}$ \\
\hline Diciembre & 23 & 44 & 15 & 44 \\
Enero & 22 & 43 & 15 & 34 \\
Febrero & 21 & 37 & 19 & 51 \\
Marzo & 18 & 38 & 21 & 65 \\
Abril & 16 & 33 & 22 & 63 \\
\hline
\end{tabular}

en los pesos de las macetas, pesadas una por una en su totalidad, utilizando una balanza digital Kretz, con precisión de 5 g y capacidad de $31 \mathrm{~kg}$. Se distribuyeron al azar 20 plantas por tratamiento por especie (180 en total) sobre una mesada y se les colocó una faja de material aislante alrededor para evitar la acción de los rayos solares sobre las macetas.

\section{Parámetros de crecimiento}

Al finalizar el ensayo (finales de abrilprincipios de mayo) se determinó el peso seco total (PST) y el peso de vástago y raíz (PSV y PSR) en 10 plantas por tratamiento por especie luego de secarlas en estufa a 70 ${ }^{\circ} \mathrm{C}$ por $72 \mathrm{~h}$. Para determinar el área foliar (AF) se tomaron 5 hojas expandidas por planta de otros 6 individuos por tratamiento por especie, y se escanearon para luego calcular el área con el programa ImageJ (National Institutes of Health).

Del total de 20 plantas por tratamiento por especie, 10 plantas fueron utilizadas sólo para determinar el PST, PSV y PSR. Otras 6 plantas fueron utilizadas para determinar AF, área foliar específica y materia seca foliar para calcular la estrategia según Grime, medir potencial hídrico y para construir curvas $\mathrm{P}-\mathrm{V}$. Las restantes no fueron utilizadas en ninguna medición y sólo se produjeron para evitar que disminuyera el número de réplicas en caso de mortandad (no se presentan los datos de mortandad).

\section{Índices ecofisiológicos}

Se calcularon algunos índices ecofisiológicos para poder comparar entre las especies estudiadas el grado de adaptación a la sequía. Con los valores de peso seco de las plantas se calculó la relación vástago-raíz como: $\mathrm{V} /$ $\mathrm{R}=\mathrm{PSV} / \mathrm{PSR}$. El área foliar específica (AFE) se determinó como AFE=AF/PS, donde las mismas hojas utilizadas para determinar el AF (cinco hojas expandidas por planta de seis individuos por tratamiento por especie) se secaron en estufa a $70{ }^{\circ} \mathrm{C}$ por $72 \mathrm{~h}$ y se pesaron para obtener su peso seco (PS). También se determinó el contenido de materia seca foliar como MSF=PS/PF, donde PF es el peso fresco de esas mismas hojas a máxima turgencia (hojas hidratadas en agua destilada por $12 \mathrm{~h}$ ).

Para comparar el efecto del estrés hídrico en las tres especies se calculó la biomasa 
proporcional de cada especie como la proporción entre la biomasa promedio alcanzada en cada tratamiento de estrés hídrico y en el tratamiento control (Villagra and Cavagnaro 2006). Se usó este cálculo basado en Munns (2002), quien reportó que la tolerancia al estrés es usualmente evaluada como la proporción de producción de biomasa bajo condiciones de estrés en relación con la producida bajo condiciones de control

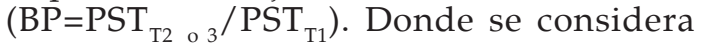
que la planta tiene mayor tolerancia al estrés cuando la biomasa proporcional se acerca más a 1, es decir que el PST bajo el tratamiento de estrés no se ve tan afectado con respecto al control (Munns 2002; Villagra and Cavagnaro 2006).

\section{Estrategias ecológicas}

Se clasificaron las tres especies según sus estrategias de acuerdo con la clasificación de Grime (1977, 2006), en competidoras (C), estréstolerantes (S) y ruderales (R). Esta clasificación se realizó a través de una herramienta de cálculo (StrateFy) calibrada a nivel global por Pierce et al. (2017), que se basa en el área foliar (AF), el área foliar específica (AFE) y el contenido de materia seca foliar (MSF). En función de estos caracteres obtenidos en las plantas bajo los tres tratamientos (medidos en 6 plantas por tratamiento por especie) se calcularon los porcentajes de las estrategias de las tres especies (\%C:\%S:\%R).

\section{Potencial hídrico}

Se determinó el potencial hídrico sobre el tallo principal inmediatamente después de haber sido cortado en el mes de marzo (plantas de 13 meses de edad). Las mediciones se realizaron el día antes a ser regadas según cada tratamiento en cuatro plantas por tratamiento por especie al pre-amanecer ( $\Psi \mathrm{pa})$, de 4:00 a 5:30 h, con una cámara de presión (Biocontrol, Buenos Aires, Argentina) según Scholander et al. (1965). No se realizaron en las 6 plantas utilizadas para las curvas $\mathrm{P}-\mathrm{V}$ ya que algunas de ellas no tenían ramificaciones para poder realizar ambas mediciones en la misma planta.

\section{Curvas presión-volumen}

Las curvas se construyeron según el método de expresión de savia (Corcuera 2003), ya que por el método de transpiración libre al cabo de un par de mediciones los tallos comenzaban a perder algunas hojas y no se podía continuar midiendo. Las mediciones fueron realizadas durante los meses de febrero y marzo (en plantas de 12 y 13 meses de edad), midiendo entre 1 y 2 plantas por día. Para realizar las curvas se cortó un brote terminal bajo agua, para alcanzar turgencia máxima se lo dejó en un recipiente de plástico con el extremo sumergido en agua, se lo cubrió con una bolsa negra y se lo dejó a temperatura ambiente de laboratorio. A la mañana siguiente, antes de comenzar con las mediciones se le cortó la base del tallo bajo agua nuevamente para evitar embolismo. Luego se obtuvo el peso con una balanza (Ohaus Pioner) de $1 \mathrm{mg}$ de precisión (peso del brote completamente hidratado) y el potencial agua ( $\Psi \mathrm{a})$ inicial con la cámara de presión (Biocontrol). Antes de colocar el brote en la cámara se lo introdujo en una bolsa para evitar la pérdida de agua por transpiración. El brote perdió agua mediante la sobrepresurización dentro de la cámara de presión y después se obtuvo un nuevo valor de $\Psi$, que dependió de la cantidad de agua perdida durante el previo periodo de sobrepresurización (Corcuera 2003). Se repitió el ciclo entre 12 y 14 veces por brote, y se llevó a cabo en 6 plantas por tratamiento por especie. Luego, los brotes se secaron en estufa a $70{ }^{\circ} \mathrm{C}$ durante 72 horas y se pesaron para obtener el peso seco. A partir de estas curvas se estimaron distintos parámetros hídricos (Tyree et al. 1978): el potencial osmótico en el punto de pérdida de turgencia $\left(\Psi_{0}{ }^{0}\right)$, el potencial osmótico a máxima turgencia $\left(\Psi_{0}{ }^{100}\right)$, el módulo de elasticidad de un tejido ( $\varepsilon)$, el contenido relativo de agua en el punto de pérdida de turgencia o punto de plasmólisis incipiente $\left(\mathrm{CRA}^{0}\right)$ y el contenido relativo de agua simplástica (S) (Corcuera 2003).

\section{Análisis estadístico}

Los datos de peso seco total (PST), potencial

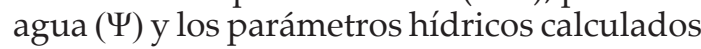
con las curvas P-V fueron sometidos a un análisis de varianza de una vía (ANOVA) con tratamiento de estrés hídrico como factor para cada especie por separado. Por otro lado, se llevaron a cabo ANOVA de dos vías para los datos calculados de AF, AFE, MSF y relación vástago-raíz $(\mathrm{V} / \mathrm{R})$, con tratamiento y especie como factores. Para comparar las medias se utilizó una prueba de Tukey con $P<0.05$. Como los datos de biomasa no cumplían el supuesto de homogeneidad de varianzas del ANOVA, se les aplicó una transformación de $\ln (x+1)$. Para el análisis estadístico se utilizó el paquete 
estadístico R Studio, con el paquete car ( $\mathrm{R}$ Core Team 2014).

\section{Resultados}

Los tratamientos de estrés hídrico aplicados afectaron la acumulación de biomasa en las tres especies. El peso seco total (PST) fue menor tanto en el tratamiento moderado (T2) como en el de estrés severo (T3) en $A$. lampa y en $S$. subulatus con respecto al control (T1), mientras que en L. cuneifolia sólo fue significativamente menor en el T3 (Figura 1). Asimismo, el área foliar (AF) también se vio afectada por el estrés hídrico en las tres especies, y fue menor en el tratamiento T3 (las hojas caídas por senescencia foliar no se tuvieron en cuenta). De las tres especies, la que presentó mayor AF y mayor área foliar específica (AFE) fue S. subulatus (Figura 2). El AFE fue significativamente menor en las plantas de $A$. lampa en comparación con las otras especies, pero no se diferenció entre los 3 tratamientos. Las plantas de $S$. subulatus bajo ambos tratamientos de estrés hídrico (T2 y T3) presentaron mayores valores de AFE que el control, lo que indica que el peso seco de sus hojas disminuye en mayor proporción que el área foliar frente a una menor disponibilidad de agua en el suelo (Figura 2). En las otras dos especies no se observaron diferencias en el AFE producto de los tratamientos aplicados.

La relación $\mathrm{V} / \mathrm{R}$ fue mayor en las plantas de $A$. lampa, es decir, esta especie asigna mayor proporción de asimilados a vástago

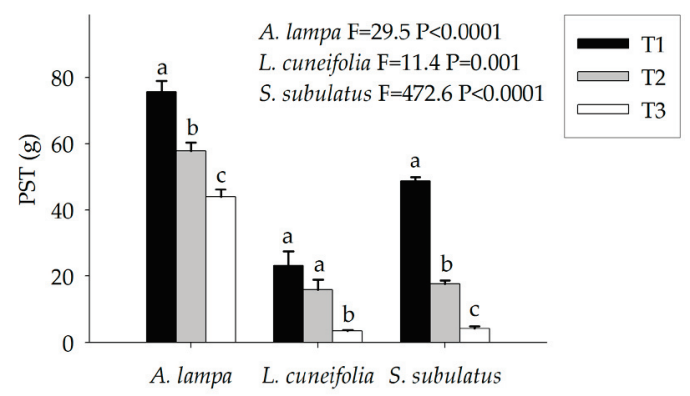

Figura 1. Peso seco total (PST) al finalizar el ensayo, en plantas de 15 meses de edad de las tres especies bajo los tratamientos de estrés hídrico $(n=10)$. Letras distintas indican diferencias significativas entre los tratamientos para cada especie $(P<0.05)$. En la figura se presentan los resultados del ANOVA. Las barras verticales indican \pm E. E. de la media.

Figure 1. Total dry weight (PST) at the end of the experiment, in 15-months-old plants of the three species, under the water stress treatments $(n=10)$. Different letters indicate significant differences between treatments $(P<0.05)$. ANOVA results are presented in the figure. Vertical bars indicate \pm S.E. of the mean. que las otras dos, pero no se diferenció significativamente entre los distintos tratamientos aplicados (Figura 2). El contenido de materia seca foliar (MSF) fue mayor en las plantas de A. lampa y L. cuneifolia, y los tratamientos no presentaron diferencias. En cuanto a la biomasa proporcional (BP), las plantas de $S$. subulatus presentaron el menor valor de las tres especies (T2=0.36, T3=0.09), lo que indica que la acumulación de biomasa bajo condiciones de estrés hídrico moderado y severo se vio afectada en una mayor proporción en comparación con las otras dos especies $(A$. lampa T2 $=0.76$ y T3=0.58; $L$. cuneifolia T2=0.69 y T3=0.14).

A través de los valores promedio de AF, AFE y MSF obtenidos (sin separar por tratamiento) se pudo calcular el porcentaje de las estrategias de Grime de cada especie. En promedio se obtuvo para $A$. lampa $\mathrm{C}=3 \%, \mathrm{~S}=97 \%$ y $\mathrm{R}=0 \%$; para L. cuneifolia $\mathrm{C}=2 \%, \mathrm{~S}=79 \%$ y $\mathrm{R}=19 \%$; y para S. subulatus $\mathrm{C}=2 \%, \mathrm{~S}=93 \%$ y $\mathrm{R}=5 \%$ (Figura 3 ). Las tres especies obtuvieron un mayor porcentaje de estrategia estrés-tolerante $(S)$ y, a su vez, L. cuneifolia obtuvo en combinación un porcentaje mayor como ruderal (R). Según los cálculos de esta herramienta, A. lampa y S. subulatus son netamente $S$ y L. cuneifolia es S/SR.

Las plantas de A. lampa y L. cuneifolia bajo estrés hídrico (T2 y T3) disminuyeron su potencial hídrico al pre-amanecer $\left(\Psi_{\mathrm{pa}}\right)$ con respecto al control, y se obtuvieron los potenciales más bajos (más negativos) en el T3. Mientras tanto, en S. subulatus sólo la media del $\Psi$ de las plantas bajo el tratamiento de estrés hídrico severo fue significativamente menor que el control (Figura 4). Las medias del $\Psi 0^{100} \mathrm{y}$ del $\Psi 0^{0}$ de $A$. lampa y L. cuneifolia sometidas a un estrés hídrico severo (T3) fueron significativamente menores que el control (Figura 4), lo que indica que estas especies realizarían ajuste osmótico para mantener la turgencia. En las plantas de $L$. cuneifolia bajo el tratamiento de estrés hídrico moderado, ambos potenciales osmóticos fueron menores al control; no así en las plantas de $S$. subulatus, en las que las medias de los distintos tratamientos no presentaron diferencias significativas (Figura 4).

El contenido relativo de agua en el punto de pérdida de turgencia $\left(\mathrm{CRA}^{0}\right)$ varió sólo en las plantas de L. cuneifolia; fue mayor la media del control que la del T3 (Figura 5). Para el contenido relativo de agua simplástica $(S)$ se observaron diferencias entre las medias de 

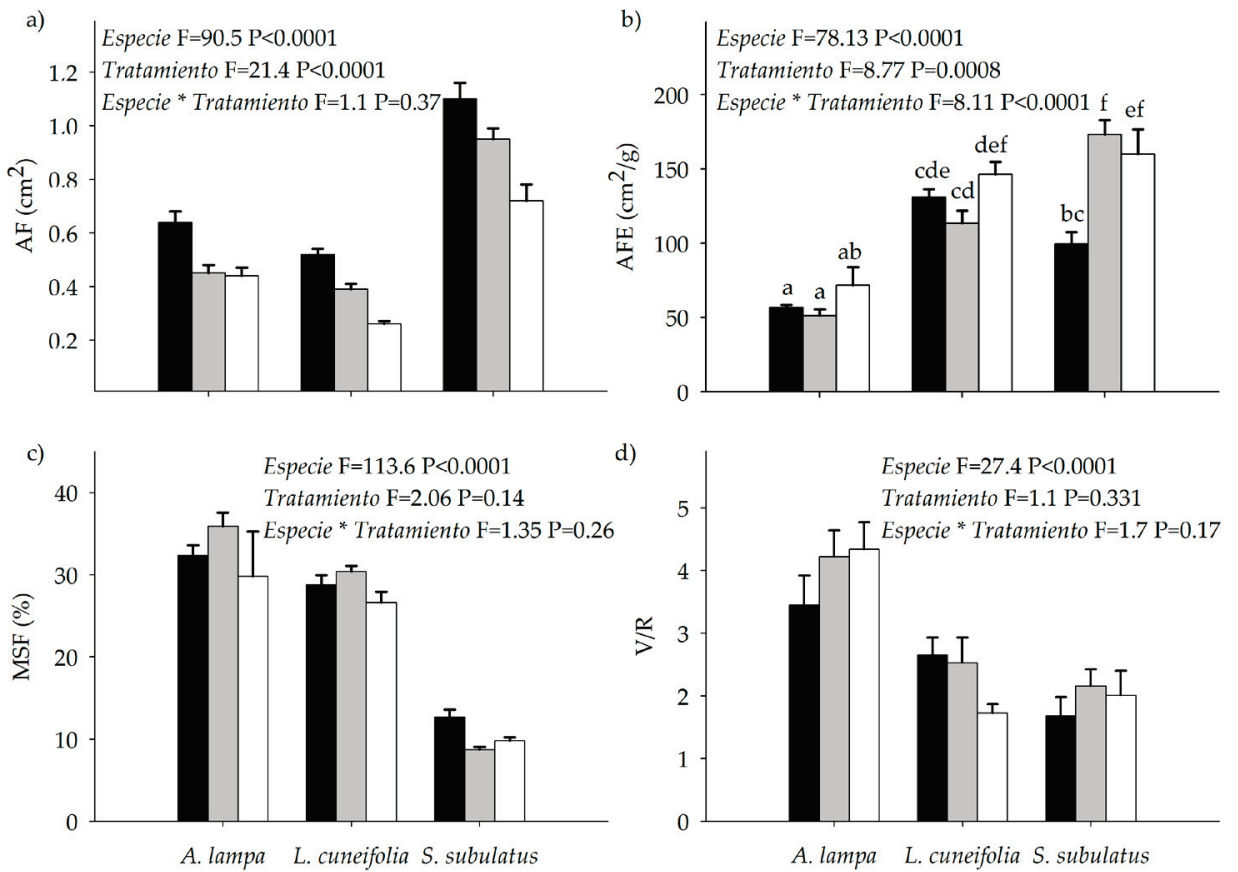

T2 $\square \mathrm{T} 2 \square \mathrm{T} 3$

Figura 2. (a) Área foliar (AF), (b) área foliar específica (AFE), (c) materia seca foliar (MSF) y (d) relación Vástago-Raíz $(\mathrm{V} / \mathrm{R})$ en plantas de 15 meses de edad de las tres especies en los tratamientos de estrés hídrico al finalizar el ensayo $(\mathrm{n}=6$; excepto para $\mathrm{V} / \mathrm{R}$, con $\mathrm{n}=10)$. Letras distintas en cada variable indican diferencias significativas entre las especies y tratamientos $(P<0.05)$. Se presentan en la figura los resultados del ANOVA. Las barras verticales indican \pm E.E. de la media.

Figure 2. (a) Leaf area (AF), (b) specific leaf area (AFE), (c) leaf dry matter (MSF) and (d) shoot-to-root ratio (V/R) in 15 -month-old plants of the three species under water stress treatments at the end of the experiment $(\mathrm{n}=6$; except for $\mathrm{V} / \mathrm{R}$, with $\mathrm{n}=10)$. Different letters indicate significant differences between species and treatments $(P<0.05)$. The ANOVA results are presented in the figure. Vertical bars indicate \pm S.E. of the mean.

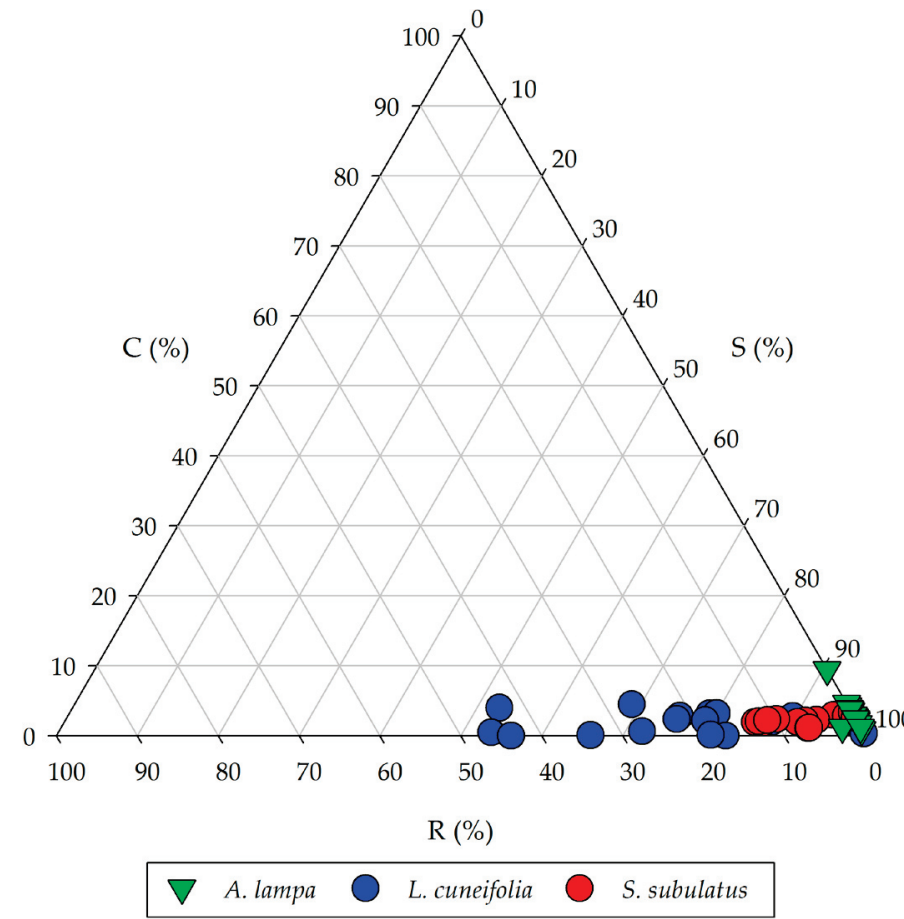

Figura 3. Estrategias de A. lampa, L. cuneifolia y S. subulatus según el Triángulo de Grime obtenidas a partir de la herramienta de cálculo CSR StrateFy $(\mathrm{C}=$ competidora, $\mathrm{S}=$ estrés-tolerante, $\mathrm{R}=$ ruderal). Cada símbolo representa una planta sin diferenciar entre los tratamientos de estrés hídrico aplicados $(\mathrm{n}=18)$.

Figure 3. Strategies of Atriplex lampa, $L$. cuneifolia y $S$. subulatus according to the Grime Triangle obtained through the CSR calculator tool StrateFy $(C=$ competitor, $\mathrm{S}=$ stress-tolerator, $\mathrm{R}=$ ruderal). Each symbol represents a plant without differentiating between water stress treatments $(\mathrm{n}=18)$. 


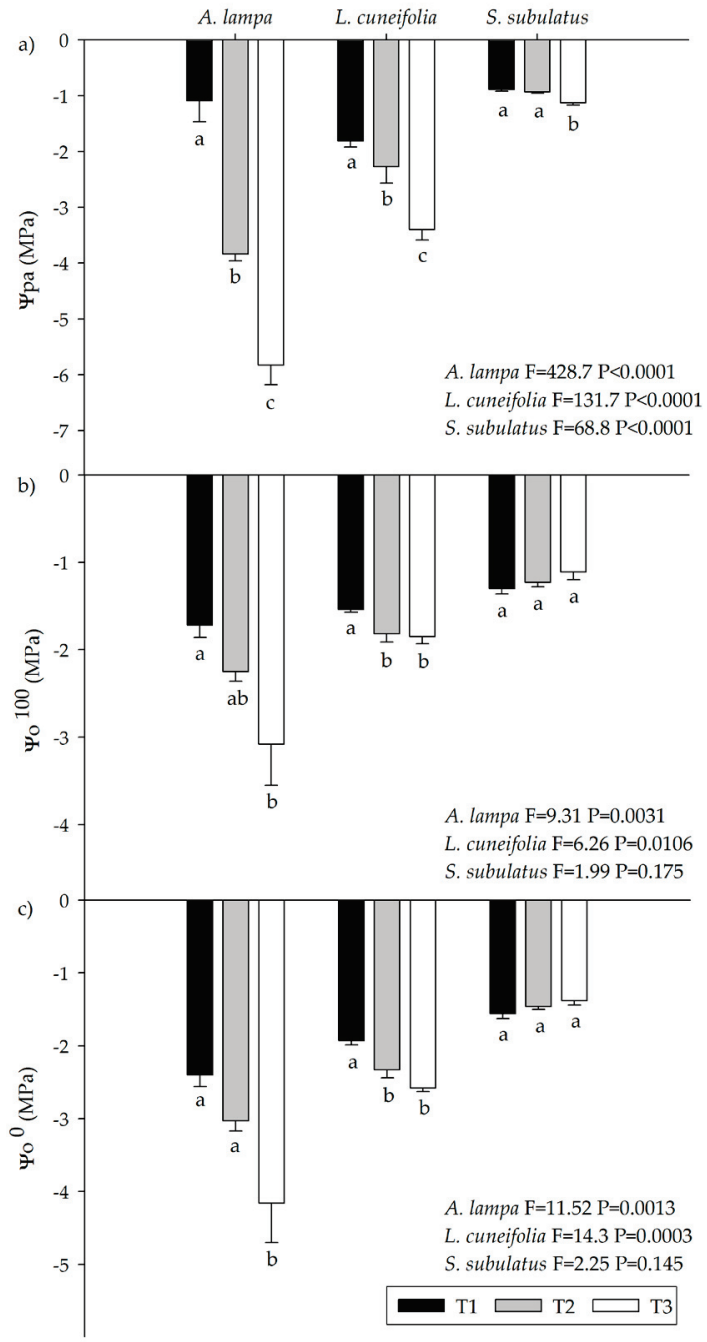

Figura 4. Potencial hídrico pre-amanecer ( $\Psi$ pa), potencial osmótico a máxima turgencia $\left(\Psi^{100}\right)$ y en el punto de pérdida de turgencia $\left(\Psi^{0}\right)$ de plantas de las tres especies bajo los tratamientos de estrés hídrico $(n=6$; excepto para $\Psi$ pa, con $n=4$ ). Letras distintas indican diferencias significativas entre tratamientos para cada especie $(P<0.05)$. Se presentan en la figura los resultados del ANOVA. Las barras verticales indican \pm E.E. de la media.

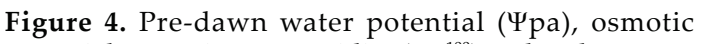
potential at maximum turgidity $\left(\Psi^{100}\right)$ and at the turgor loss point $\left(\Psi^{0}{ }^{0}\right)$ of plants of the three species under water stress treatments ( $n=6$; except for $\Psi$ pa, with $n=4)$. Different letters indicate significant differences between treatments for each species $(P<0.05)$. ANOVA results are presented in the figure. Vertical bars indicate \pm S.E. of the mean.

los tratamientos en las plantas de A. lampa. En dicho caso, el $\mathrm{S}$ fue mayor en las plantas que estaban en condiciones de estrés hídrico severo, lo que indicaría una mayor fracción de agua simplástica con respecto al control (Figura 5). La media del módulo de elasticidad de los tejidos $(\varepsilon)$ calculado no varió entre los

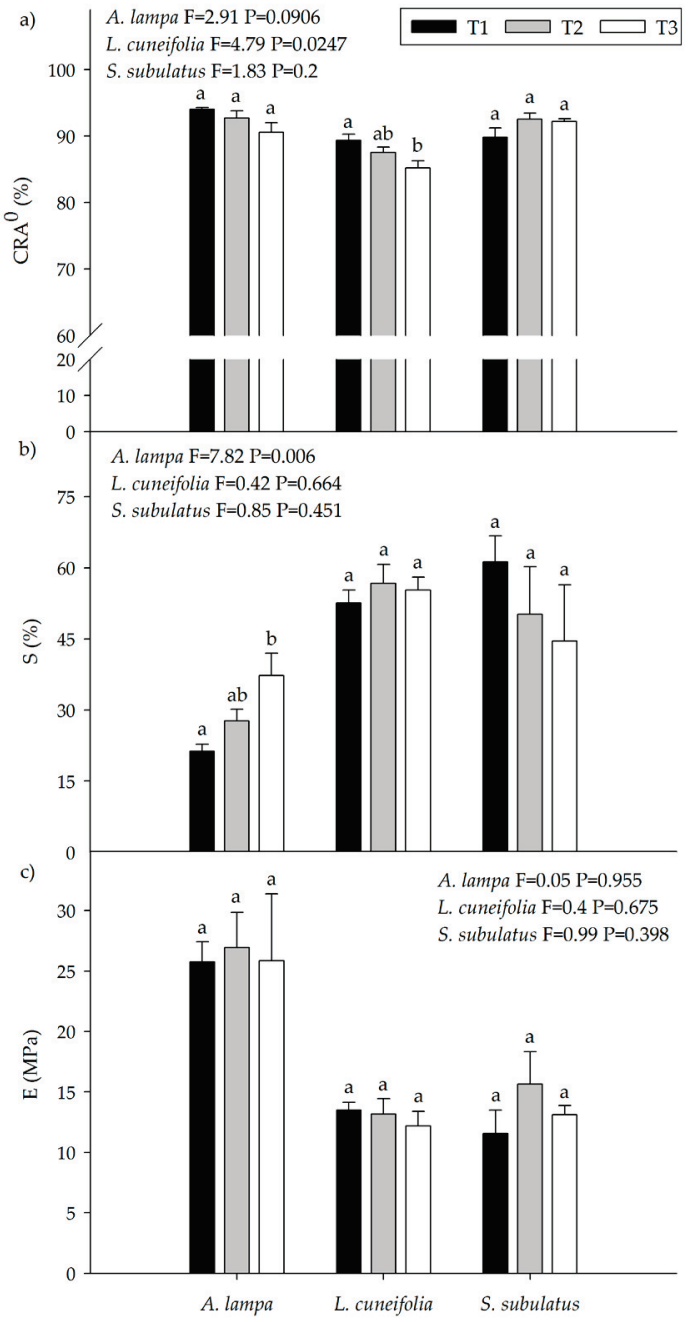

Figura 5. Contenido relativo de agua en el punto de pérdida de turgencia $\left(\mathrm{CRA}^{0}\right)$, contenido de agua simplástica (S) y módulo de elasticidad $(\varepsilon)$ de plantas de las tres especies bajo los tratamientos de estrés hídrico $(n=6)$. Letras distintas indican diferencias significativas entre tratamientos para cada especie $(P<0.05)$. Se presentan en la figura los resultados del ANOVA. Las barras verticales indican \pm E.E. de la media.

Figure 5. Relative water content at the turgor loss point $\left(\mathrm{CRA}^{0}\right)$, simplastic water content $(\mathrm{S})$ and modulus of elasticity $(\varepsilon)$ of plants of the three species under water stress treatments $(n=6)$. Different letters indicate significant differences between treatments for each species $(P<0.05)$. ANOVA results are presented in the figure. Vertical bars indicate \pm S.E. of the mean.

distintos tratamientos aplicados en ninguna de las tres especies (Figura 5).

\section{DisCUSIÓN}

Los tratamientos de estrés hídrico aplicados en las tres especies produjeron cambios en los parámetros ecofisiológicos de las plantas. Estos cambios fueron similares en A. lampa y 
L. cuneifolia, mientras que S. subulatus presentó una respuesta diferente. En condiciones de estrés hídrico, las primeras dos tienen la capacidad de realizar ajuste osmótico, lo que las habilita a seguir extrayendo agua del suelo; tienen hojas pequeñas, más esclerófilas (menor área foliar específica y mayor contenido de materia seca foliar) y su crecimiento no se ve tan afectado. S. subulatus no realiza ajuste osmótico, tiene una mayor área foliar, hojas poco esclerófilas y en condiciones de elevado estrés hídrico presenta una severa disminución de su crecimiento.

Tanto la acumulación de materia seca como el área foliar en las tres especies disminuyeron significativamente por el estrés hídrico, pero esa disminución fue proporcionalmente mayor en $S$. subulatus y la que menos se vio afectada fue $A$. lampa. La materia seca acumulada bajo el T2 y T3 llego a ser, en promedio, un 64\% y $90 \%$ menor con respecto al control en S. subulatus, lo que indica que el crecimiento de esta especie sería más afectado por el estrés hídrico que el de las otras 2 especies (24\% y $42 \%$ para $A$. lampa, 31\% y $85 \%$ para L. cuneifolia). Villagra y Cavagnaro (2006) midieron la biomasa proporcional (BP) en dos especies arbustivas nativas del Monte y también observaron una menor BP en Prosopis alpataco con respecto a $P$. argentina, lo cual está relacionado con el carácter más xerofítico de esta última.

Las especies con estrategias de tipo estrés tolerantes tienden a tener baja área foliar específica (AFE) y alto contenido de materia seca foliar (MSF), que de acuerdo con las variaciones de la economía foliar a nivel mundial son indicadores claros de un comportamiento conservativo (Pierce et al. 2013). Estas características fueron observadas principalmente en $A$. lampa, mientras que las plantas de L. cuneifolia presentaron valores más intermedios en su AFE. Por el contrario, las hojas de S. subulatus no presentaron un comportamiento conservativo (menor contenido de MSF y una mayor AFE) en comparación con las otras dos especies.

Una disminución de la relación vástago/raíz es una adaptación que presentan muchas especies del Monte a la escasez de agua (Vilela et al. 2003; Villagra and Cavagnaro 2006), ya que las plantas asignan una mayor proporción de asimilados al sistema radical, donde pueden apoyar el crecimiento de las raíces mientras exploran más suelo en búsqueda de agua y mantienen un mejor estado hídrico (Taiz and Zeiger 2002; Pugnaire et al. 2006). En el presente estudio no se observó este ajuste en la relación $\mathrm{V} / \mathrm{R}$, pero en ensayos similares plantas de A. lampa (Caraciolo et al. 2002; Passera et al. 2010; Fernández et al. 2018) y L. cuneifolia (Fernández et al. 2016) asignaron mayor proporción de materia seca a sus raíces en condiciones de estrés hídrico. En otras especies arbustivas del Monte Austral, Cella Pizarro y Bisigato (2010) no observaron modificaciones en la asignación de biomasa debido al estrés hídrico. Estos autores resaltan la importancia de tener en cuenta el efecto del estrés hídrico sobre el tamaño de la planta para diferenciar si la variación en la asignación de biomasa es producto del tamaño de la planta o del tratamiento de estrés hídrico. Por otro lado, los diferentes resultados observados en la relación $V / R$ pueden ser producto del tamaño de maceta utilizado en los distintos estudios. Cuando se compara el crecimiento de una especie utilizando múltiples tamaños de macetas, se ha observado un menor crecimiento en macetas más pequeñas, 1o cual estaría relacionado principalmente con una disminución de la fotosíntesis por unidad de área foliar (Fernandez 2010; Poorter et al. 2012). En el caso de S. subulatus, no se han observado modificaciones en la partición de asimilados al igual que en el presente estudio (Fernández et al. 2015).

Al utilizar los valores de AF, AFE y MSF para calcular el tipo de estrategia a través de la herramienta StrateFy (Pierce et al. 2017), se pudo observar que $A$. lampa es de las tres especies la que más se asemeja a una típica especie con estrategia estrés-tolerante. A pesar de las múltiples diferencias observadas en $S$. subulatus con respecto a las otras dos especies, dicha herramienta le asignó un mayor porcentaje como estrés-tolerante que como ruderal. Es fundamental tener en cuenta que en este estudio se trabajó con plantines de 1 año de edad en invernáculo, por lo que los valores de los caracteres foliares medidos y de los distintos parámetros hídricos pueden ser distintos a los que se observan en el campo. Las temperaturas máximas que se producen dentro del invernáculo son mayores a las que se dan en el campo y, como ya se mencionó antes, el tamaño de las macetas también puede influir en el tiempo en el que se desarrolla la sequía, que puede ser mucho más rápido que en el campo y no permitir la aclimatación de la planta (Fernández 2010).

Pierce et al. (2017) mencionan como especie característica de arbustales desérticos a $L$. 
divaricata, la que a través de esta herramienta arroja valores de 1:99:0\%, estrategia netamente estrés-tolerante. Mientras tanto, en nuestro caso, L. cuneifolia tuvo un mayor porcentaje de ruderal (2:79:19\%). Estos mismos autores mencionan que es necesario tener en cuenta la variación ecotípica a lo largo del área de distribución de una especie y su plasticidad fenotípica, ya que se podría ampliar el rango de variación de la estrategia calculada (Pierce et al. 2017). A pesar de no obtener los resultados esperados para $S$. subulatus, esta herramienta de cálculo de estrategias resulta muy interesante debido al escaso número de caracteres necesarios para calcularla, la relativa sencillez en su medición, y la posibilidad de comparación entre especies con distintas formas de vida. Por esta razón resulta muy práctica y aplicable para seleccionar especies adecuadas para programas de restauración, ya que permite comparar las estrategias de las distintas especies según los micrositios que se deseen restaurar, o según el objetivo planteado.

Por otro lado, los estudios sobre los efectos de la humedad del suelo en el crecimiento de las plantas indican una relación fuerte entre el potencial agua y el crecimiento, por lo que la medición del potencial agua es uno de los indicadores de estrés hídrico más adecuados (Taiz and Zeiger 2002). La diferencia en los potenciales agua observados en $S$. subulatus (potenciales más altos) con respecto a las otras dos especies puede ser producto de que esta tiene hojas suculentas (Ruiz Leal 1972). Aunque el agua almacenada en las hojas puede contribuir sólo con un pequeño porcentaje del total del agua transpirada diariamente, esta puede ayudar a contrarrestar el desbalance entre la demanda de agua por transpiración de las hojas y la disponibilidad de agua en el suelo (Sack and Tyree 2005; Ogburn and Edwards 2010). En Atriplex lampa y L. cuneifolia se midieron valores muy bajos de potencial agua, llegando a -5.7 MPa y -9 MPa, respectivamente, sin producir la muerte de las plantas (Passera et al. 2010; Fernández et al. 2016).

En respuesta a los tratamientos de estrés hídrico aplicados, se pudo observar que $A$. lampa y L. cuneifolia tienen la capacidad de modificar las características fisiológicas a nivel foliar. Esto se manifestó a través de la disminución del $\Psi$ o a saturación y en el punto de pérdida de turgencia $\left(\Psi^{0}\right)$. Los $\Psi_{0}$ obtenidos a través de las curvas $\mathrm{P}-\mathrm{V}$ podrían indicar que las plantas de $A$. lampa y $L$. cuneifolia realizaron ajuste osmótico frente a la menor disponibilidad hídrica en el suelo del T3. Además, está ampliamente probado que el $\Psi^{0}$ es un predictor fuerte de la tolerancia al estrés hídrico en las plantas (Bartlett et al. 2012).

Aunque el ajuste osmótico es costoso en términos energéticos por la acumulación de solutos orgánicos o inorgánicos, particularmente escasos en estos ambientes (Abril et al. 2009), los $\Psi$ bajos son necesarios para que la planta siga extrayendo agua del suelo con baja disponibilidad hídrica. Este ajuste también fue observado por Passera et al. (2010) en A. lampa, con potenciales osmóticos de hasta -8.8 MPa medidos por técnicas de psicrometría. Esta diferencia amplia con los Yo obtenidos en este trabajo puede estar relacionada con la metodología empleada para su medición, ya que en plantas de Atriplex se recomienda determinar el $\Psi$ o con curvas $\mathrm{P}-\mathrm{V}$ para evitar posibles filtraciones de sales presentes en vesículas de la epidermis, que pueden suceder con los métodos destructivos (Teixeira Lins et al. 2018).

Por otro lado, los valores de $\Psi_{\text {pa }}$ observados en las plantas de A. lampa y L. cuneifolia bajo T2 y T3 son menores que el potencial osmótico en el punto de pérdida de turgencia $\left(\Psi_{0}{ }^{0}\right)$ determinado a través de estas curvas, lo que nos indicaría pérdida de turgencia. Este efecto fue observado en otras especies de la estepa patagónica (Iogna et al. 2011) y en L . tridentata (Meinzer et al. 1986, 1988), en las que al realizar la hidratación de las muestras para construir las curvas P-V se produce una modificación de los parámetros medidos, en algunos casos de hasta $3 \mathrm{MPa}$, lo que determina turgencias negativas. En nuestro caso, los resultados obtenidos a modo comparativo entre tratamientos y especies pueden ser útiles, pero sería conveniente revisar estos resultados realizando las curvas $\mathrm{P}-\mathrm{V}$ sin hidratar los tallos como indican estos autores (Meinzer et al. 1986; Iogna et al. 2011).

Con las curvas $\mathrm{P}-\mathrm{V}$ también se pudo determinar el módulo de elasticidad ( $\varepsilon$ ), pero, en general, estos valores no suelen presentar un patrón consistente de variación a lo largo de gradientes xéricos-mésicos (Castro-Díez and Navarro 2007). En las especies aquí estudiadas $\varepsilon$ no varió producto del estrés hídrico, pero se observó una menor elasticidad (mayor $\varepsilon$ ) en las plantas de $A$. lampa con respecto a las otras dos. Esto fue considerado en muchos casos como una ventaja en especies que acumulan una gran cantidad de solutos orgánicos, ya que 
implica que una disminución de la turgencia y del $\Psi$ está acompañada de una pequeña disminución del contenido de agua de la planta. Esto permitiría una recuperación más rápida luego de un periodo de estrés (Corcuera et al. 2002; Hessini et al. 2009). Por otro lado, las plantas de L. cuneifolia en condiciones de estrés hídrico severo, además de realizar ajuste osmótico presentaron menores valores de contenido relativo de agua en el punto de pérdida de turgencia $\left(\mathrm{CRA}^{0}\right)$, lo que podría indicar que esta especie tiene una mayor tolerancia a la desecación de sus tejidos (Serrano et al. 2005). En Larrea tridentata de Norteamérica, el mantenimiento de la turgencia ha sido asociado a cambios en la elasticidad de los tejidos (Meinzer et al. 1988), a diferencia de lo observado en L. cuneifolia.

Muchos mecanismos de tolerancia a la sequía también están relacionados con caracteres a nivel foliar. Las especies que presentan menores potenciales osmóticos en el punto de pérdida de turgencia $\left(\Psi^{0}\right)$ suelen tener hojas más escleromórficas (menor área foliar específica, AFE) (Bucci et al. 2004; Iogna et al. 2011). Esto se observó en $A$. lampa, que presentó los valores de AFE más bajos y la mayor variación en el $\Psi_{0}^{0}$ entre el control y el tratamiento de mayor estrés hídrico, lo que sugiere que el mantenimiento de la turgencia es crucial para mantener hojas con altos costos estructurales (Bucci et al. 2004; Iogna et al. 2011).

Las diferentes características observadas en las tres especies también están relacionadas con su distribución natural, donde a A. lampa y L. cuneifolia se las observa en los sitios más secos del Monte (Ruiz Leal 1972; Roig 1976), mientras que $S$. subulatus está presente en áreas con suelos profundos donde se acumula agua de lluvia, en suelos montañosos erosionados hídricamente, como también en los de erosión eólica, en dunas, abanicos aluviales y costados de caminos (Roig 1976; Martínez Carretero 1993; Méndez et al. 1993; Castro et al. 2013).

Teniendo en cuenta los resultados obtenidos podemos decir que $S$. subulatus no posee mecanismos para hacer frente a condiciones de estrés hídrico severo, por lo que se debería utilizar en micrositios donde se acumule agua o en proyectos en los que se pueda realizar un aporte extra de agua a la planta. Esta especie es interesante porque fructifica luego del primer año de plantada (Dalmasso and Martínez Carretero 2013), lo que permite la revegetación natural del sitio degradado, y porque tiene alta tasa germinativa, no requiere tratamientos pre-germinativos (Fernández et al. 2015; Massini et al. 2016; Perez et al. 2019a) y no es palatable para el ganado (Guevara et al. 1999). Pérez et al. (2019a) observaron una alta sobrevivencia de esta especie luego de un año del trasplante, pero al segundo año, la sobrevivencia disminuyó (84\% y 32\% respectivamente), mientras que la de $A$. lampa en el mismo sitio se mantuvo (91\% en ambos años de medición). Esto puede reflejar las diferentes adaptaciones al estrés hídrico observadas en el presente estudio y el rol que pueden llegar a cumplir estas especies en los programas de restauración. En otros trabajos también se menciona que $S$. subulatus posee tasas de crecimiento altas y conductancias estomáticas elevadas (Dalmasso and Martínez Carretero 2013; Fernández et al. 2015; Perez et al. 2019a). En algunos sitios degradados por la actividad petrolera, se observó que S. subulatus luego de 4 años de haber sido trasplantada alcanzó un diámetro mayor de copa igual al 137\% del testigo medido en el campo natural y una altura del 97\% (Dalmasso and Martínez Carretero 2013). En ese mismo estudio, plantas de $A$. lampa trasplantadas alcanzan un diámetro mayor de copa igual al $109 \%$ y una altura correspondiente al 51.3\% del testigo medido en el campo natural.

En cuanto a Atriplex lampa y L. cuneifolia, por sus características de estrés-tolerantes son adecuadas para utilizarlas en programas de restauración a lo largo y ancho del Monte, en particular en sitios extremadamente secos, de difícil acceso o donde no se puedan aplicar técnicas que mejoren la disponibilidad hídrica del suelo. En la actualidad, A. lampa es una de las especies más utilizadas en programas de restauración de zonas áridas en el país (Becker et al. 2013; Dalmasso 2010; Dalmasso and Martínez Carretero 2013; Pérez et al. 2019a), ya que posee altas tasas de crecimiento, tiene la capacidad de adaptarse a diferentes ambientes, tolera concentraciones salinas altas y usa más y mejor el recurso hídrico (Passera and Borsetto 1989; Passera et al. 2010; Dalmasso and Martínez Carretero 2013). Sin embargo, se debe considerar la utilización de protectores para las plantas o el cierre con alambrado del sitio a restaurar durante los primeros años, ya que esta especie es consumida tanto por el ganado caprino como bovino (Allegretti et al. 2012).

Por el contrario, L. cuneifolia, a pesar de ser una de las especies más abundantes del Monte, no ha sido tan ampliamente incorporada en 
programas de restauración debido a problemas con su germinación y producción en vivero (Pérez et al. 2019a; Fernández et al. 2019). Esta especie tiene la capacidad de colonizar los lugares más calientes y secos del Monte, no sólo por todas las características antes descriptas, sino también porque sus hojas y ramas están orientadas con el frente hacia el este, lo que le permite evadir físicamente el sol del mediodía e interceptar la radiación solar durante las primeras horas de la mañana y en las últimas horas de la tarde (Ezcurra et al. 1991).

La restauración ecológica de zonas áridas está creciendo de forma exponencial a nivel global, pero aún se enfrenta a muchos desafíos y a un alto costo económico (Vallejo 2009; Yirdaw et al. 2017; Pérez et al. 2019b). Tener en cuenta los resultados obtenidos en este tipo de estudios es imprescindible para una correcta selección de las especies a utilizar en programas de restauración y para mejorar su eficiencia.

Agradecimientos. En memoria de S. Trione mentor e impulsor de muchas de las ideas aquí plasmadas. Agradezco la colaboración en los ensayos de H. Debandi y G. Zalazar, la ayuda de L. Biruk para aplicar la metodología de las curvas P-V, y las correcciones y sugerencias de C. Passera al manuscrito. Este trabajo fue parcialmente financiado por la Agencia Nacional de Promoción Científica y Tecnológica y CONICET.

\section{REFERENCIAS}

Abraham, E. M. 2002. Lucha contra la desertificación en las tierras secas de Argentina; el caso de Mendoza. Pp. 2744 in A. Fernández Cirelli and E. M. Abraham (eds.). El agua en Iberoamérica. De la escasez a la desertificación. Cooperación Iberoamericana CYTED Programa Iberoamericano de Ciencia y Tecnología para el Desarrollo, Buenos Aires, Argentina.

Allegretti, L., C. Sartor, S. Paez Lama, V. Egea, M. Fucili, and C. Passera. 2012. Effect of the physiological state of Criollo goats on the botanical composition of their diet in NE Mendoza, Argentina. Small Ruminant Research 103(2-3):152157. https://doi.org/10.1016/j.smallrumres.2011.09.018.

Abril, A., P. Villagra, and L. Noe. 2009. Spatiotemporal heterogeneity of soil fertility in the Central Monte desert (Argentina). Journal of Arid Environments 73:901-906. https:/ /doi.org/10.1016/J.JARIDENV.2009.04.019.

Adhikari, A., and J. D. White. 2014. Plant water use characteristics of five dominant shrub species of the Lower Rio Grande Valley, Texas, USA: Implications for shrubland restoration and conservation. Conservation Physiology 2: cou005. https://doi.org/10.1093/conphys/cou005.

Barbour, M. G., D. V. Díaz, and R. W. Breidenbach. 1974. Contributions to the biology of Larrea species. Ecology 55: 1199-1215. https:/ / doi.org/10.2307/1935450.

Bartlett, M. K., C. Scoffoni, and L. Sack. 2012. The determinants of leaf turgor loss point and prediction of drought tolerance of species and biomes: a global metaDanalysis. Ecology Letters 15:393-405. https://doi.org/10.1111/j.14610248.2012.01751. .

Bateman, A., W. Lewandrowski, J. C. Stevens, and M. Muñoz-Rojas. 2018. Ecophysiological indicators to assess drought responses of arid zone native seedlings in reconstructed soils. Land Degradation and Development 29:984-993. https: //doi.org/10.1002/ldr.2660.

Becker, G. F., J. C. Bustos, C. R. López, and J. A. Ayesa. 2013. Experiencias de revegetación de explanadas con especies nativas. Pp. 202-212 en D. R. Pérez, A. E. Rovere and M. E. Rodriguez-Araujo (eds.). Restauración Ecológica en la Diagonal Árida de la Argentina. Vázquez Mazzini, Buenos Aires.

Bisigato, A. J., and M. B. Bertiller. 1999. Seedling emergence and survival in contrasting soil microsites in Patagonian Monte shrubland. Journal of Vegetation Science 10:335-342. https:/ / doi.org/10.2307/3237062.

Bochet, E., and P. García-Fayos. 2015. Identifying plant traits: A key aspect for species selection in restoration of eroded roadsides in semiarid environments. Ecological Engineering 83:444-451. https://doi.org/10.1016/ j.ecoleng.2015.06.019.

Bonvissuto, G. L., and C. A. Busso. 2013. Establecimiento de plántulas en microambientes del Monte Austral Neuquino. Pp. 96-111 en D. R. Pérez, A. E. Rovere and M. E. Rodriguez-Araujo (eds.). Restauración Ecológica en la Diagonal Árida de la Argentina. Vázquez Mazzini, Buenos Aires.

Bosco, T., M. B. Bertiller, and A. L. Carrera. 2018. Abiotic factors affect the recruitment and biomass of perennial grass and evergreen shrub seedlings in denuded areas of Patagonian Monte rangelands. Journal of Environmental Management 218:118-128. https:/ / doi.org/10.1016/J.JENVMAN.2018.04.020.

Bucci, S. J., G. Goldstein, F. C. Meinzer, F. G. Scholz, A. C. Franco, and M. Bustamante. 2004. Functional convergence in hydraulic architecture and water relations of tropical savanna trees: From leaf to whole plant. Tree Physiology 24: 891-899. https://doi.org/10.1093/treephys/24.8.891.

Caraciolo, M., L. I. Allegretti, C. B. Passera, and C. Robles. 2002. Efecto de diferentes niveles de salinidad sobre el crecimiento de Atriplex lampa. Revista de la Facultad de Ciencias Agrarias 34:101-106.

Castro, M. L., G. A. Zuleta, A. A. Pérez, M. E. Ciancio, P. Tchilinguirian, and C. A. Escartín. 2013. Rehabilitación de estepas arbustivas en locaciones petroleras del Monte Austral. Evaluación de la técnica del escarificado I: Vegetación. Pp. 225-245 en D. R. Pérez, A. E. Rovere and M. E. Rodríguez-Araujo (eds.). Restauración Ecológica en la Diagonal Árida de la Argentina. Vázquez Mazzini, Buenos Aires. 
Castro-Díez, P., and J. Navarro. 2007. Water relations of seedlings of three Quercus species: variations across and within species grown in contrasting light and water regimes. Tree Physiology 27:1011-8. https://doi.org/10.1093/ treephys/27.7.1011.

Cella Pizarro, L. C., and A. J. Bisigato. 2010. Allocation of biomass and photoassimilates in juvenile plants of six Patagonian species in response to five water supply regimes. Annals of Botany 106:297-307. doi.org/10.1093/aob/ mcq109.

Corcuera, L. 2003. Comparación de dos métodos para generar curvas presión-volumen en especies del género Quercus. Forest Systems 12:111-121.

Corcuera, L., J. J. Camarero, and E. Gil-Pelegrín. 2002. Functional groups in Quercus species derived from the analysis of pressure-volume curves. Trees 16:465-472. https://doi.org/10.1007/s00468-002-0187-1.

Dalmasso, A. D., and E. Martinez Carrtero. 2013. Revegetación de áreas degradadas. Estudio de caso en plataformas petroleras en Malargüe, Mendoza. Pp. 275-292 en D. R. Pérez, A. E. Rovere and M. E. Rodriguez-Araujo (eds.). Restauración Ecológica en la Diagonal Árida de la Argentina. Vázquez Mazzini, Buenos Aires.

Dalmasso, A. D. 2010. Revegetación de áreas degradadas con especies nativas. Boletín Sociedad Argentina de Botánica 45:149-171.

Delatorre-Herrera, J., I. Delfino, C. Salinas, H. Silva, and L. Cardemil. 2010. Irrigation restriction effects on water use efficiency and osmotic adjustment in Aloe Vera plants (Aloe barbadensis Miller). Agricultural Water Management 97: 1564-1570. https://doi.org/10.1016/j.agwat.2010.05.008.

Ezcurra, E., C. Montana, and S. Arizaga. 1991. Architecture, light interception, and distribution of Larrea species in the Monte desert, Argentina. Ecology 72:23-34. https://doi.org/10.2307/1938899.

Fernández, M. E., M. A. Cony, and C. B. Passera. 2019. Germination temperatures and seed dormancy of two Larrea species (Zygophyllaceae) from the Monte desert, Argentina. Rev. de la Facultad de Ciencias Agrarias 51:235-247.

Fernández, M. E., M. A. Cony, and C. B. Passera. 2015. Respuestas fisiológicas de plantines de Senecio subulatus a diferentes niveles de suministro de agua. Pp. 233-241 en Martínez Carretero, E. and A. Dalmasso (eds). Restauración Ecológica en la Diagonal Árida de la Argentina 2. CONICET, Mendoza, Argentina.

Fernández, M. E., C. B. Passera, and M. A. Cony. 2016. Sapling growth, water status and survival of two native shrubs from the Monte desert, Mendoza, Argentina, under different preconditioning treatments. Revista de la Facultad de Ciencias Agrarias 48:33-47.

Fernández, M. E., C. I. Pissolito, and C. B. Passera. 2018. Water and nitrogen supply effects on four desert shrubs with potential use for rehabilitation activities. Plant Ecology 219:789-802. https://doi.org/10.1007/s11258-018-0834-2.

Fernández, R. J. 2010. Control versus realismo en estudios ecofisiológicos. Opciones de diseño y procedimientos en experimentos de sequía. Pp. 13-23 en M. E. Fernández, J. E. Gyenge (eds.). Técnicas de medición en ecofisiología vegetal. Conceptos y procedimientos. INTA, Buenos Aires.

Fisher, F., J. Zak, G. Cunningham, and W. Whitford. 1988. Water and nitrogen effects on growth and allocation patterns of creosotebush in the northern Chihuahuan Desert. Journal of Range Management 41:387-391. https://doi.org/ $10.2307 / 3899572$.

Galmés, J., M. A. Conesa, J. M. Ochogavía, J. A. Perdomo, D. M. Francis, M. Ribas-Carbó, R. Savé, J. Flexas, H. Medrano, and J. Cifre. 2011. Physiological and morphological adaptations in relation to water use efficiency in Mediterranean accessions of Solanum lycopersicum. Plant, Cell and Environment 34:245-260. https://doi.org/10.1111/j.13653040.2010.02239.x.

Grime, J. P. 2006. Plant strategies, vegetation processes, and ecosystem properties. John Wiley and Sons. West Sussex, England.

Grime, J. P. 1977. Evidence for the existence of three primary strategies in plants and its relevance to ecological and evolutionary theory. The American Naturalist 111:1169-1194. https://doi.org/10.1086/283244.

Guevara, J. C., C. R. Stasi, C. F. Wuilloud, and O. R. Estevez. 1999. Effects of fire on rangeland vegetation in southwestern Mendoza plains (Argentina): composition, frequency, biomass, productivity and carrying capacity. Journal of Arid Environments 41:27-35. https:/ doi.org/10.1006/jare.1998.0463.

Hessini, K., J. P. Martínez, M. Gandour, A. Albouchi, A. Soltani, and C. Abdelly. 2009. Effect of water stress on growth, osmotic adjustment, cell wall elasticity and water-use efficiency in Spartina alterni ora. Environmental and Experimental Botany 67:312-319. https://doi.org/10.1016/j.envexpbot.2009.06.010.

Iogna, P. A., S. J. Bucci, F. G. Scholz, and G. Goldstein. 2011. Water relations and hydraulic architecture of two Patagonian steppe shrubs: Effect of slope orientation and microclimate. Journal of Arid Environments 75:763-772. https://doi.org/10.1016/j.jaridenv.2011.04.001.

Labraga, J. C., and R. Villalba. 2009. Climate in the Monte Desert: Past trends, present conditions, and future projections. Journal of Arid Environments 73:154-163. https://doi.org/10.1016/J.JARIDENV.2008.03.016.

Lambers, H., F. S. Chapin, and T. L. Pons. 2008. Plant physiological ecology. Second Edi. Springer, New York. https: //doi.org/10.1007/978-0-387-78341-3.

Martínez, J. P., H. Silva, J. F. Ledent, and M. Pinto. 2007. Effect of drought stress on the osmotic adjustment, cell wall elasticity and cell volume of six cultivars of common beans (Phaseolus vulgaris L.). European Journal of Agronomy 26:30-38. https://doi.org/10.1016/j.eja.2006.08.003.

Martínez Carretero, E. 1993. Carta de vegetación del sector Cerro de Casa de Piedra-San Isidro (Hoja Mendoza 23021). Multequina 2:89-140.

Masini, A. C. A., A. E. Rovere, and G. I. Pirk. 2016. Germination of Gutierrezia solbrigii and Senecio subulatus, endemic 
Asteraceae from Argentina. Phyton 85:314-323.

Meinzer, F. C., P. W. Rundel, M. R. Sharifi, and E. T. Nilsen. 1986. Turgor and osmotic relations of the desert shrub Larrea tridentata. Plant, Cell and Environment 9:467-475. https:/ /doi.org/10.1111/j.1365-3040.1986.tb01762.x.

Meinzer, F. C., M. R. Sharifi, E. T. Nilsen, and P. W. Rundel. 1988. Effects of manipulation of water and nitrogen regime on the water relations of the desert shrub Larrea tridentata. Oecologia 77:480-486. https://doi.org/10.1007/ BF00377263.

Méndez, E., E. Martínez Carretero, and C. Wuilloud. 1993. La vegetación de las reservas naturales de la provincia de Mendoza. III. La vegetación del campo experimental El Divisadero, Sta. Rosa. Parodiana 8:113-123.

Munns, R. 2002. Comparative physiology of salt and water stress. Plant, Cell and Environment 25:239-250. https: //doi.org/10.1046/j.0016-8025.2001.00808.x.

Noy-Meir, I. 1973. Desert ecosystems: Environment and producers. Annual Review of Ecology and Systematics 4:25-41. https://doi.org/10.1146/annurev.es.04.110173.000325.

Nunes, A., G. Oliveira, T. Mexia, A. Valdecantos, C. Zucca, E. A. C. Costantini, E. M. Abraham, A. P. Kyriazopoulos, A. Salah, R. Prasse, O. Correia, S. Milliken, B. Kotzen, and C. Branquinho. 2016. Ecological restoration across the Mediterranean Basin as viewed by practitioners. Science of the Total Environment 566:722-732. https://doi.org/ 10.1016/j.scitotenv.2016.05.136

Ogburn, R. M., and E. J. Edwards. 2010. The ecological water-use strategies of succulent plants. Advances in Botanical Research 55:179-225. https://doi.org/10.1016/B978-0-12-380868-4.00004-1.

Oliet, J., R. Planelles, M. López Arias, and F. Artero. 2002. Soil water content and water relations in planted and naturally regenerated Pinus halepensis Mill. seedlings during the first year in semiarid conditions. New Forests 23:31-44. https: //doi.org/10.1023/A:1015668815037.

Padilla, F. M., R. Ortega, J. Sánchez, and F. I. Pugnaire. 2009. Rethinking species selection for restoration of arid shrublands. Basic and Applied Ecology 10:640-647. https://doi.org/10.1016/j.baae.2009.03.003.

Padilla, F. M., and F. I. Pugnaire. 2004. El uso de especies arbustivas para la restauración de la cubierta vegetal en ambientes semiáridos. Cuadernos de la Sociedad Española de Ciencias Forestales 17:103-107.

Padilla, F. M., and F. I. Pugnaire. 2006. The role of nurse plants in the restorationof degraded environments the restoration of degraded environments. Frontiers in Ecology and the Environment 4:196-202. https://doi.org/10.1890/15409295(2006)004[0196:TRONPI]2.0.CO;2

Passera, C. B., J. B. Cavagnaro, and C. E. Sartor. 2010. Plantas C3, C4 y CAM nativas del monte árido argentino. Adaptaciones y potencial biológico. Pp. 165-176 en J. L. González Rebollar and A. Chueca Sancho (eds.). C4 y CAM. Características generales y uso en programas de desarrollo de tierras áridas y semiáridas. CSIC, Madrid, España.

Passera, C. B. 1990. Efecto de la temperatura y del estrés hídrico en la germinación de "Atriplex lampa" moq. (Chenopodiaceae). Studia Oecologica 7:77-84.

Passera, C. B., and O. Borsetto. 1989. Aspectos ecológicos de Atriplex lampa. Investigación Agraria: Producción y Protección Vegetales. INIA 4:179-198.

Pérez, D. R., F. M. Farinaccio, and J. Aronson. 2019a. Towards a dryland framework species approach. Research in progress in the Monte Austral of Argentina. Journal of Arid Environments 161:1-10. https://doi.org/10.1016/ j.jaridenv.2018.09.001.

Pérez, D. R., F. González, C. Ceballos, M. E. Oneto, and J. Aronson. 2019b. Direct seeding and outplantings in drylands of Argentinean Patagonia: estimated costs, and prospects for large'scale restoration and rehabilitation. Restoration Ecology 27:1105-1116. https://doi.org/10.1111/rec.12961.

Pierce, S., G. Brusa, I. Vagge, and B. E. L. Cerabolini. 2013. Allocating CSR plant functional types: The use of leaf economics and size traits to classify woody and herbaceous vascular plants. Functional Ecology 27:1002-1010. https: //doi.org/10.1111/1365-2435.12095.

Pierce, S., D. Negreiros, B. E. L. Cerabolini, J. Kattge, S. Díaz, M. Kleyer, B. Shipley, S. J. Wright, N. A. Soudzilovskaia, V. G. Onipchenko, P. M. van Bodegom, C. Frenette-Dussault, E. Weiher, B. X. Pinho, J. H. C. Cornelissen, J. P. Grime, K. Thompson, R. Hunt, P. J. Wilson, G. Buffa, O. C. Nyakunga, P. B. Reich, M. Caccianiga, F. Mangili, R. M. Ceriani, A. Luzzaro, G. Brusa, A. Siefert, N. P. U. Barbosa, F. S. Chapin, W. K. Cornwell, J. Fang, G. W. Fernandes, E. Garnier, S. Le Stradic, J. Peñuelas, F. P. L. Melo, A. Slaviero, M. Tabarelli, and D. Tampucci. 2017. A global method for calculating plant CSR ecological strategies applied across biomes world-wide. Functional Ecology 31:444-457. https://doi.org/10.1111/1365-2435.12722.

Poorter, H., J. Bühler, D. van Dusschoten, J. Climent, and J. A. Postma. 2012. Pot size matters: a meta-analysis of the effects of rooting volume on plant growth. Functional Plant Biology 39:839-850. doi.org/10.1071/FP12049.

Pugnaire, F. I., F. S. Chapin, and T. M. Hardig. 2006. Evolutionary changes in correlations among functional traits in Ceanothus in response to Mediterranean conditions. Web Ecology 6:17-26. https://doi.org/10.5194/we-6-17-2006.

Roig, F.A., M. M. González Loyarte, E. M. Abraham, E. Mendez, V. G. Roig, and E. Martínez Carretero. 1991. Maps of desertification hazard of Central Western Argentina (Mendoza Province) study case. In N. Middleton, and D. S. G. Thomas (eds.), World Atlas of Thematic Indicators of Desertification. UNEP, London.

Roig, F.A. 1976. Las comunidades vegetales del piedemonte de la precordillera de Mendoza. ECOSUR Argentina 3: $1-45$.

Rossi, B. E., and P. E. Villagra. 2003. Effects of Prosopis exuosa on soil properties and the spatial pattern of understorey species in arid Argentina. Journal of Vegetation Science 14:543-550. doi:10.1111/j.1654-1103.2003.tb02181.x

Rovere, A. E. 2015. Review of the science and practice of restoration in Argentina: increasing awareness of the discipline. Restoration Ecology 23:508-512. https://doi.org/10.1111/rec.12240. 
Ruiz Leal, A. 1972. Flora popular mendocina. Deserta 3. IADIZA. Mendoza. Pp. 296.

Rundel, P. W., P. E. Villagra, M. O. Dillon, S. Roig-Juñent, and G. Debandi. 2007. Arid and semi-arid ecosystems. Pp. 158-183 in O. A. Veblen TT and K. Young (eds.). The Physical Geography of South America. Oxford Univ-ersity Press, Oxford.

Sack, L., and M. T. Tyree. 2005. Leaf hydraulics and its implications in plant structure and function. Vascular Transport in Plants. Pp. 93-114 in Vascular Transport in Plants. A volume in Physiological Ecology. https://doi.org/10.1016/ B978-012088457-5/50007-1.

Sandquist, D. R., and J. R. Ehleringer. 1998. Intraspecific variation of drought adaptation in brittlebush: Leaf pubescence and timing of leaf loss vary with rainfall. Oecologia 113:162-169. https://doi.org/10.1007/s004420050364.

Scholander, P. F., H. T. Hammel, D. E. Bradstreet, and E. A. Hemmingsen. 1965. Sap pressure in vascular plants. Science NY. 148:339-346. https:/ / doi.org/10.1126/science.148.3668.339.

Serrano, L., J. Peñuelas, R. Ogaya, and R. Savé. 2005. Tissue-water relations of two co-occurring evergreen Mediterranean species in response to seasonal and experimental drought conditions. Journal of Plant Research 118:263-269. https: //doi.org/10.1007/s10265-005-0220-8.

Soriano, A., O. E. Sala, and S. B. Perelman. 1994. Patch structure and dynamics in a Patagonian arid steppe. Vegetatio 111:127-135. https://doi.org/10.1007/BF00040332.

Taiz, L., and E. Zeiger. 2002. Plant physiology. Sinauer Associates, Massachusetts, USA.

Teixeira Lins, C. M., E. Rodrigues de Souza, H. Farias de Melo, M. K. Silva Souza Paulino, P. R. Dourado Magalhães, L. Yago de Carvalho Leal, and H. R. Bentzen Santos. 2018. Pressure-volume (P-V) curves in Atriplex nummularia Lindl. for evaluation of osmotic adjustment and water status under saline conditions. Plant Physiology and Biochemistry 124:155-159. https://doi.org/10.1016/j.plaphy.2018.01.014.

Trione, S. O., and C. B. Passera. 1993. Growth and nitrogen status of Atriplex lampa seedlings under different water regimes. Journal of Arid Environments 25:331-341. https://doi.org/10.1006/jare.1993.1066.

Tyree, M. T., M. E. MacGregor, A. Petrov, and M. I. Upenieks. 1978. A comparison of systematic errors between the Richards and Hammel methods of measuring tissue - water relations parameters. Canadian Journal of Botany 56: 2153-2161. https://doi.org/10.1139/b78-257.

Valladares, F., A. Vilagrosa, J. Peñuelas, R. Ogaya, J. J. Camarero, L. Corcuera, S. Sisó, and E. Gil-Pelegrín. 2004. Estrés hídrico: ecofisiología y escalas de la sequía. Pp. 163-190 en F. Valladares (ed.). Ecología del bosque mediterráneo en un mundo cambiante. 2da. edición. Naturaleza y Parques Nacionales. Ministerio de Medio Ambiente. EGRAF S. A. Madrid.

Vallejo, R., A. Smanis, E. Chirino, D. Fuentes, A. Valdecantos, and A. Vilagrosa. 2012. Perspectives in dryland restoration: Approaches for climate change adaptation. New Forests 43:561-579. https://doi.org/10.1007/s11056-012-9325-9.

Vallejo, V. R. 2009. Problems and perspectives of dryland restoration. Pages 13-22 in S. Bautista, J. Aronson and V. R. Vallejo (eds.). Land Restoration to Combat Desertification: Innovative Approaches, Quality Control and Project Evaluation. Fundación Centro de Estudios Ambientales del Mediterráneo, CEAM, Valencia, Spain.

Vilela, A. E., M. J. Rennella, and D. A. Ravetta. 2003. Responses of tree-type and shrub-type Prosopis (Mimosaceae) taxa to water and nitrogen availabilities. Forest Ecology and Management 186:327-337. https://doi.org/10.1016/S03781127(03)00299-8.

Villagra, P. E., and J. B. Cavagnaro. 2006. Water stress effects on the seedling growth of Prosopis argentina and Prosopis alpataco. Journal of Arid Environments 64:390-400. https://doi.org/10.1016/j.jaridenv.2005.06.008.

Villagra, P. E., C. Giordano, J. A. Álvarez, J. B. Cavagnaro, A. Guevara, C. Sartore, C. B. Passera, and S. A. Greco. 2011. Ser planta en el desierto: estrategias de uso de agua y resistencia al estres hidrico en el monte central de Argentina. Ecología Austral 21:29-42.

de Villalobos, A. E., and D. V. Peláez. 2001. Influences of temperature and water stress on germination and establishment of Prosopis caldenia Burk. Journal of Arid Environments 49:321-328. https://doi.org/10.1006/jare.2000.0782.

Yirdaw, E., M. Tigabu, and A. Monge. 2017. Rehabilitation of degraded dryland ecosystems - review. Silva Fennica 51:1-32. https://doi.org/10.14214/sf.1673. 